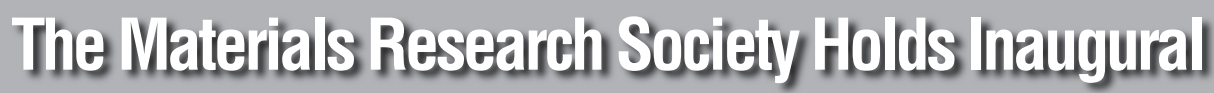 Inienalitonal Meeifing in Gintha wili G-Vilis www.mrs.org/IMRC2008
}

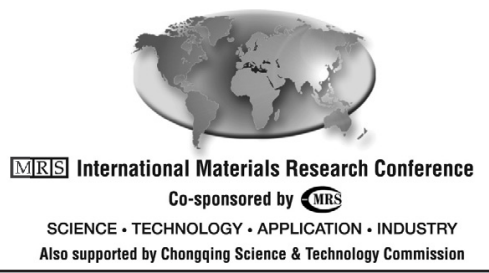

The 2008 International Materials Research Conference (2008-IMRC) was held from June 9-12, 2008, in Chongqing, China, organized jointly by the Materials Research Society (MRS) and the Chinese Materials Research Society (C-MRS). The city of Chongqing, located in Western China, is one of four large municipalities in China, with over 30 million people. The conference had the strong support of the Chongqing Science and Technology Commission (CSTC) and the Chongqing Municipal Government. Paul C.W. Chu (Hong Kong University of Science and Technology, China and University of Houston, USA), Eric Garfunkel (Rutgers University, USA), Sung-su Han (LG Electronics Institute of Technology, Korea), and Yafang Han (Executive Director of C-MRS, China) chaired the conference.

"Tonight, in early summer, the 'mountain city' is bright because of your presence, coming from different countries," said Xiaorui Chen, director of the Department of International Cooperation of CSTC during the Welcome Reception. Conference chairs Y. Han and Garfunkel welcomed everyone to the conference, thanking those who helped initiate and organize the conference. They also addressed the recent earthquake in Sichuan province not far from Chongqing and encouraged friends to continue with contributions to the relief efforts.

The following morning, during the Opening Ceremony, Garfunkel acknowledged 2008-IMRC as the first MRS meeting held outside the United States. This meeting comes at a special time in history with the confluence of two forces, globalization of science and technology and the realization that current world problems are global-such as energy demandrequiring international cooperation, with materials research at the core of this effort, he said. The focus on globalization and the energy theme woven into the conference program were reiterated by Chu and by 2008 Immediate Past President of MRS, Alan J. Hurd (Los Alamos National Laboratory, USA). Executive Vice-Mayor of Chongqing, Qifan Huang, emphasized the recent rapid growth in science and technology in Chongqing, and the development of various materials-related industries. President of C-MRS, Boyun Huang (Central South University, China), announced that the Meeting had received close to 3000 abstracts from 49 countries.

\section{Keynote Addresses}

The Meeting offered five keynote presentations and nine technical sessions. In the first keynote address, Gang Wan, the Minister of Science and Technology in China, offered congratulations and a warm welcome to conference participants. He expressed a conviction that this landmark conference would have farreaching impact on both China and the United States, and he presented an optimistic view of the future of materials research in Chinese society. He cited the positive effects of biotechnology research in the realms of agriculture, forestry, and environmental protection, recalling the great success of genetically modified cotton in reducing pesticide use and increasing production. Such innovation in the field of materials research stands to decrease the costs and expedite the manufacture of products like computer chips, Wan said, which is important for education and the general well-being of citizens. He cited climate change as another crucial area where China is keen to apply the power of materials engineering, and he lauded the advances made to ensure environmentally-friendly Olympic Games in Beijing that summer. He also reminded the audience of the important role that materials technologies played in the rescue and aid efforts following the recent devastating earthquake in nearby Sichuan province and expressed gratitude for international support received in the wake of that crisis.

"Energy, energy, energy, everybody is talking about energy!" So began Nobel laureate Alan J. Heeger of the University of California, Santa Barbara, who gave a keynote presentation on the future of polymers for photovoltaic applications. The peak in world energy production has already been reached and exceeded, but the demand continues to grow as China and India become more industrialized, he said. Energy will become a major international issue together with global warming, and new sources of energy must be found, Heeger said. Direct energy from the sun is clearly one answer, since the amount of sunlight energy falling on the earth in one hour is equivalent to all the energy needs of the world for one year.

Heeger showed results on the outdoor lifetime of polymeric photovoltaic devices placed on his own rooftop. The performance of polymeric photovoltaic devices, unlike other semiconductors, improves when the temperature is raised, which makes rooftop applications very appropriate. When a photon strikes a material such as a fullerene, he said, the ultrafast charge separation is 1000 times faster than any of the competing recombination processes so that the quantum efficiency approaches unity. The challenge is to find a material that has charge separating junctions "everywhere" and these have to be formed on a nanometer scale in order to collect the fairly low mobility electrons. This challenge is met with a self-assembling polymer matrix that contains a network of fullerene derivatives P3HT (poly-3-hexylthiophene) and PCBM ([6,6]-phenyl-C61-butyric acid methyl ester) molecules. To this are added two contacts of dissimilar metals with different work functions so that electrons move toward the lower work function metal. Unfortunately, the open circuit voltage in these materials is low, but annealing of the material can increase the open circuit voltage.

Single-layer solar cells of P3HT have been made with efficiencies greater than $5 \%$ but the bandgap is too large, so that a large fraction of the red end of the solar spectrum is not captured. Recent developments in semiconductor polymers with lower bandgaps could lead to the more efficient capture of red light, which could lead to improvements in the efficiency of single cells to $7 \%$ and to over $10 \%$ in a tandem cell. Multilayer tandem cells, like those made using II-V materials, open possibilities of improvements of up to $50 \%$. New architectures, new polymers, better charge collection, increased open circuit voltage, and tandem cell construc- 
tion are all improvements that have been demonstrated individually. The trick is to put them all in one device, Heeger said. He also discussed the use of titanium dioxide to stabilize solar cells. His goal is to produce a roll-to-roll-produced flexible polymer formed by low-cost printing that would conform to the contours of his roof and have an efficiency of $10-15 \%$.

Keynote speaker Lawrence L. Kazmerski, director of the National Center for Photovoltaics at the National Renewable Energy Laboratory, Colorado, also addressed solar energy. He said that the success of photovoltaics will require pursuing investments along evolutionary, disruptive, and revolutionary pathways, and requires a focus on both research and policy. In particular, the need to accelerate the time it takes to go from laboratory research to discovery to manufacturing should be a few years, not decades. Industry-driven evolutionary directions in the three-to-fiveyear range for first- and second-generation solar cells include lower silicon feedstock prices, thinner silicon wafers, and thin films, as well as improved processing, performance, and integration than is currently available. Disruptive technologies in the 5-to-15-year range that trump some current technologies include thin films, concentrators, organics, silicon wafers thinner than $100 \mu \mathrm{m}$, and silicon solar cells beyond 25\% efficiency. Sanyo, SunPower, and BP Saturn presently produce modules with efficiencies over 20\%, Kazmerski said. Revolutionary basic-research-driven developments in the 15-year or more cate- gory for third-generation PVs include quantum dots, nanotechnology, multijunction cells, thermophotonics, and bioinspired concepts, he said.

In a keynote address on the topic of semiconductor nanostructures and quantum dots, Wang Zhanguo from the Chinese Academy of Sciences, Beijing, discussed work specifically on the wetting layer formed during Stranski-Krastinow (SK) growth of InAs/GaAs quantum dots. The InAs amount in the wetting layer and its segregation coefficient were determined and found to be sensitive to the growth modes including SK, Frank van der Merwe (FM), and Volmer-Weber (island). The segregation coefficient varies linearly with the InAs fraction in the wetting layer. The nucleation and growth of InAs quantum
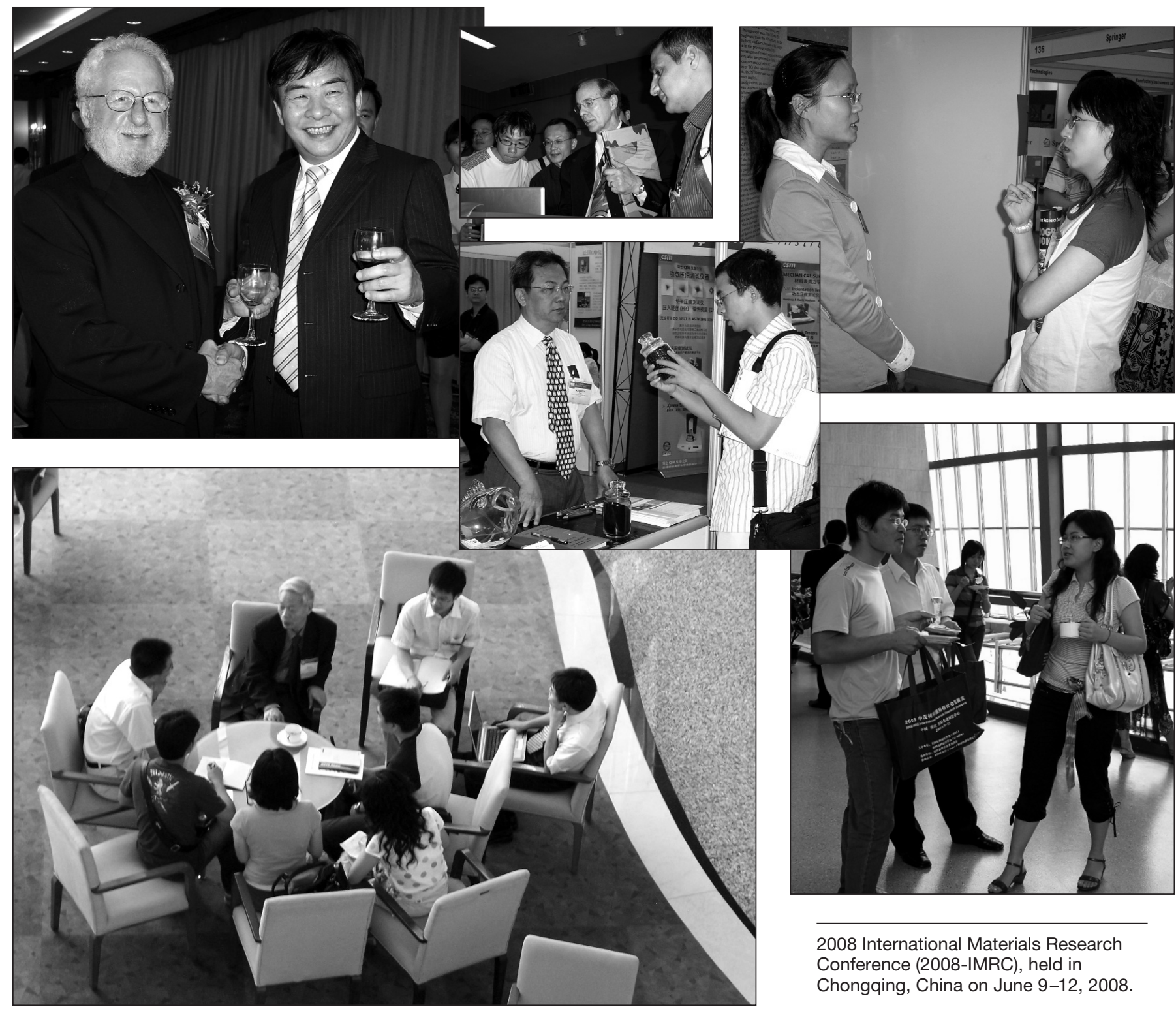

2008 International Materials Research Conference (2008-IMRC), held in

Chongqing, China on June 9-12, 2008. 
dots were found to be continuous, and both the number of quantum dots and their volume increased with deposition time according to well-defined power law equations. Under optimized growth conditions, he reported that it is now possible to grow GaAs- and InP-based nanostructures free of defects, with good uniformity, and well-spatially-ordered.

Connecting the gulf between materials research and architectural-as in building-design, keynote speaker and architect Jeffrey Holmes from the firm of Skidmore, Owings and Merrill, LLP, described the mutual responsibility both disciplines have for the future health of both the natural and built environments. Holmes said that, worldwide, buildings account for $40 \%$ of energy use and for $33 \%$ of $\mathrm{CO}_{2}$ emissions. Furthermore, by 2050 , he said that $80 \%$ of the world's population-according to estimates by the United Nations-will live in cities of over five million people and that currently three billion tons of construction materials are consumed annually worldwide with 136 million tons of construction and demolition waste generated annually in the United States alone. This information leads to the challenge architects and materials researchers face to find ways to work together to create smarter, lighter, stronger, more efficient, less wasteful, environmentally benign structures, Holmes said. He said that buildings can and should be able to conserve natural resources. High-performance glass coatings, for example, allow sunlight in, while keeping heat out, while simultaneously maximizing natural light - that is, allowing visible light in, while reflecting ultraviolet and infrared wavelengths. He described the use of ethylene-tetra-fluoroethylene (ETFE) as layers between supports or as air trapping layers. The National Swimming Centre for the 2008 Beijing Olympics, known as the Water Cube, features 100,000 $\mathrm{m}^{2}$ of ETFE foils.

In terms of using stronger materials, Holmes described "concrete cloth" that consists of a three-dimensional fiber matrix containing a specially formulated dry concrete mix that, when water is added, becomes a strong, durable, waterproof, and fireproof concrete surface. Ductile concrete incorporates layers of glass fibers into a concrete matrix to substantially increase bending strength while using substantially less material than conventional concrete reinforced with steel. Such a material could be crucial for earthquake-resistant structures. Fiber-reinforced polymers are also being extensively used as building materials. These will play a major role in the One World Trade Center building which is going to be built in New York City at the site of the original World Trade Center twin towers.

\section{Energy and Environment}

Many practical issues relating to environmental topics were addressed in Symposium A on Eco/Environmental Materials. X. Cao (Chongqing Univ. of Science and Technology) described the development of an atmospheric corrosion monitor. Composed as a stack of Fe and $\mathrm{Cu}$ layers separated by thin insulating films, the device was tested in laboratory and city environments. The current across the device resulting from electrochemical reactions on the exposed surfaces changes with variations in humidity and chemical composition of the surrounding environment. Cao reported positive correlation of current with humidity as well as $\mathrm{SO}_{2}$ and chloride content of city air. The device response to the chemical environment changed over the course of months, however, as the surface became progressively more corroded.

Also addressing the problem of air pollution was R. Ran (Tsinghua Univ.), whose work with doped $\mathrm{LaMn}_{0.9} \mathrm{Ni}_{0.1} \mathrm{O}_{3}$ strives to improve the oxygen storage capacity of that material toward the goal of reduced vehicle emissions. Ran reported that increased Sr content improved oxygen storage capacity and that Sr-doped samples were more resistant to hydrothermal aging. A. Sayari (Univ. of Ottawa) has examined how to controllably expand pore sizes of micelle structures for catalysis, with a focus on pore-expanded mesoporous silicas. These materials have high surface areas $\left(800-1200 \mathrm{~m}^{2} / \mathrm{g}\right)$, large pore sizes (up to $25 \mathrm{~nm}$ ), and large pore volumes (up to $3.6 \mathrm{~cm}^{3} / \mathrm{g}$ ). Pore-expanded mesoscopic silica for this study was prepared through post-synthesis hydrothermal treatment of as-synthesized material in the presence of dimethyldecylamine as a swelling agent. The micelles have layers that are hydrophobic and hydrophilic, stabilized with surfactants. Removing a surfactant closer to the middle of the micelle leads to an expanded pore size.

Thermoelectrics present the alluring prospect of generating electricity from a simple heat gradient. L. Wang (Chinese Academy of Sciences) improved the thermoelectric figure of merit for Gasubstituted Ge-based clathrates. During a presentation in Symposium B, she said that these materials promise good thermoelectric properties but improved thermal conductivity is needed before they can be used for practical applications. She reported strong dependence of carrier concentration and thermoelectric proper- ties on Ga doping levels in sintered $(\mathrm{Sr}, \mathrm{Ba})_{8} \mathrm{Ga}_{16} \mathrm{Ge}_{30}$, suggesting this as an approach to control and improve the figure of merit.

\section{Electronic and Ceramic Materials}

In Symposium C on Electronic Packaging Materials, K. Zhang (North Univ. of China) described a microelectromechanical system hydrophone device using a novel application of a mass-beam accelerometer structure to measure sound waves. He likened his device to stereocilia in living systems such as the cochlea and on fish lateral lines. The deflection of the sensing beam when sound waves impinge upon it is detected by a network of piezoresistors that are arms in Wheatstone bridge circuits. The sensitivity of the hydrophone is $-170 \mathrm{~dB}$.

Zinc oxide is a semiconductor with wide bandgap and a large exciton binding energy that has applications in electronic and optoelectronic devices. It can also be made into a dilute magnetic semiconductor for spintronics and offers a material that can span both magnetic and semiconductor applications. It is also a piezoelectric material for actuators and sensors. The problem with the material is that it is $n$-type as grown but the doping level is difficult to control. It is also difficult to achieve reliable $p$-type doping with low resistivity. As presented in Symposium D on Electronic Materials, to achieve lowtemperature doping of zinc oxide nanostructures, J.B. Cui (Univ. of Arkansas at Little Rock) used electrochemical growth to produce $\mathrm{ZnO}$ nanowires on silicon substrates with low-temperature doping of $\mathrm{Ni}$ and Co. It was demonstrated that dopants were incorporated into the $\mathrm{ZnO}$ because of changes in the lattice constant. Low temperature ferromagnetism was observed in these doped nanowire arrays.

T. Wu (Nanyang Technological Univ.) described methods for making different shapes of copper silicides. The silicides were grown in a simple furnace with a $\mathrm{CuO}$ plus graphite source which was held at $960^{\circ} \mathrm{C}$, with the silicon substrate held at $850^{\circ} \mathrm{C}$. Orienting the wafer in different directions yielded nano-triangles (111), nano-squares (100), and nanowires (110) of $\mathrm{Cu}_{2} \mathrm{Si}$. In the area of materials and processes for flat-panel displays, covered in Symposium E, some of the highlights reported addressed organic thin-film transistors, carbon nanotube field-emitters, and a unified thermodynamic model for metal-induced crystallization of amorphous semiconductors. The motivation for the thermodynamic model is to determine why the crystallization temperature is lowered, why it is different for different 
metals, and whether the temperature can be predicted and controlled. Z. Wang (Max Planck Inst. for Metals Research, Stuttgart) has developed a unified thermodynamic model that works for several systems. For $\mathrm{Al} / \mathrm{a}-\mathrm{Si}$, the crystallization of the amorphous $\mathrm{Si}$ initiates only at the $\mathrm{Al}$ grain boundaries and not at the $\mathrm{Al} / \mathrm{Si}$ interface. For $\mathrm{Al}$ on amorphous $\mathrm{Ge}$, re-crystallization occurs at both the $\mathrm{Al}$ grain boundaries and at the interface. For Au on a-Si, crystallization cannot start at Au grain boundaries or at the interface, but metastable $\mathrm{c}-\mathrm{Au}_{3} \mathrm{Si}$ can form at $\mathrm{Au}$ grain boundaries at very low temperatures. Interface thermodynamics play a major role. Wang was also able to control the re-crystallization temperature of a-Si with the use of ultrathin $\mathrm{Al}$ layers by varying the thickness of the film.

A major problem in the development of organic thin-film transistors is the change observed in drain current with time. S.-D. Wang (RIKEN) investigated the three major parameters that might contribute to this change: channel mobility, threshold voltage, and contact resistance. He made a series of transistors with various channel lengths, demonstrating that the mobility was not changing. Gold and copper top gate contacts behave differently, and much more variation of the contact resistance was exhibited with the gold electrodes. Wang concluded that the contact region is a large contributor to the bias stress instability on organic thin-film transistors and that the devices with a copper top gate contact have less deep traps and therefore higher operational stability. Wang proposes that these deep trap states cause the bias stress effects. During the subsequent question-and-answer session, it was suggested that a thin layer of copper oxide under the copper gate contact might help the stability.

F. Jin (Ball State Univ., Illinois) said that carbon nanotubes (CNTs) are natural field emitters because of their shape. By sputtering barium strontium oxide onto the nanotubes, Jin achieved a low work function material that enhances thermionic emission from the CNTs by a factor of 1000 .

In Symposium $F$ on Functional Ceramics, X. Yao (Xi'an Jiaotong Univ. and Tongii Univ.) presented an overview of electromagnetic ceramics. For perspective, he outlined the history of ceramic technology, beginning with pottery developed 1200 years ago and continuing up to the appearance of electromagnetic ceramics 60 years ago. Yao described the progression of electromagnetic ceramics from multiphase to single-phase and predicted that hybrid ceramics will feature once again in the future. He identified four main avenues of current development in which the first direction is utilization of grains and grain boundaries over which researchers are gaining control through tools such as hybrid ceramic processing techniques. The second area he cited was thick films, on the order of 1-10 $\mu \mathrm{m}$, typically overlooked in favor of thin films but presenting many advantages over their thinner counterparts. Third, Yao promoted composite ceramics, current work on which suggests they may be valuable in supercapacitor applications. And fourth, he said that as new ceramics become available at lower temperatures, and polymer temperature resistance rises, there is a potential for ceramic-polymer hybrid structures in the future.

While there are numerous reasons for developing fuel cell technology, the specific motivation cited by E. Traversa (Univ. of Rome Tor Vergata) was the 2003 blackout in Rome that interrupted the first La Notte Bianca (White Night) cultural event. A less centralized power system would have avoided the problem, and Traversa made the case for a system that relies on multiple sources of energy, including fuel cells. The bulk of his presentation focused on the miniaturization of solid oxide fuel cells for portable electronics, using pulsed laser deposition to build structures of layered thin films, thus controlling crystal structure, microstructure, and stoichiometry.

With the belief that a superconducting power grid could virtually eliminate power losses in transmission, D. Peterson (Los Alamos Natl. Lab.) gave an overview encouraging research moving toward that goal. He explained that superconductors must remain in the "operational envelope" defined by critical current density, Curie temperature, and magnetic field, and that maximizing performance within this envelope is the central challenge in designing high-temperature superconductors (HTS) power lines. The working design is a tape-like geometry in which multilayers of oxide materials are deposited in thin films, each on the order of $10-100 \mathrm{~nm}$ in thickness, where the superconducting component is typically $\mathrm{YBa}_{2} \mathrm{Cu}_{3} \mathrm{O}_{7}$ (YBCO). Tapes of this basic design have been constructed up to kilometer lengths with critical currents 200-250 A/cm. Prototype systems are currently being tested at several sites in the United States, said Peterson.

\section{Superalloys}

In the drive for higher efficiency and higher power output gas turbines for aerospace, power generation, and other applications, new materials are needed that endure higher temperatures without mechanical degradation. In Symposium G on Transportation Materials, S. Tin (Illinois Inst. of Technology) presented developments on nickel-based superalloys, materials that are well-suited for high-temperature operation. In particular, he focused on high-refractory content single-crystal Ni-based superalloys to understand manufacturing and solidification-related defects. A particular focus was on creep resistance, which at lower temperatures can be optimized by controlling crystal orientation and reducing lattice misfit. At higher temperatures, the challenge is to reduce diffusion and the formation of topologically closed-packed (TCP) structures. In intermediate temperatures, dislocation activity is confined to the gamma phase, and thus overall strength can be increased by strengthening the gamma phase. Adding elements such as $W$ and Re can achieve this strengthening, to a degree. However, defects such as "freckle formation" can occur due to segregation of Re to dendrite cores. Tin said that adding $\mathrm{Ru}$ (about 3\%) to the mix reduced the kinetics and can reduce formation and growth of TCPs and thus improve phase stability. $\mathrm{Ru}$ diffusion is slow, but also it slows the diffusion of Re. The reduction of the TCP phases prevents Re from being depleted from the gamma matrix, and the presence of $\mathrm{Re}$ in the gamma matrix prevents coarsening of the gamma prime phase, and structural integrity is retained at high temperatures. A remaining problem, however, is its poor oxidation resistance, Tin said.

In Symposium $\mathrm{H}$ on Magnesiumwhich was co-sponsored by the Minerals, Metals \& Materials Society-Q. Liu of the National Engineering Research Center for $\mathrm{Mg}$ Alloys in Chongqing described the establishment of the center and its various research activities. The center, directed by Fusheng Pan, was established in 2001 with the support of Chongqing University and the Chongqing government. In 2007, it was approved to be a National Center by the Ministry of Science and Technology of China. The center has established collaborations with over 50 magnesium industries throughout China. Liu discussed basic research activities on wrought $\mathrm{Mg}$ alloys. He also discussed work on developing processing technologies for wrought $\mathrm{Mg}$ alloys and concluded his presentation with a description of some of the promising applications of $\mathrm{Mg}$ alloy sheets.

K.S. Shin (Seoul Natl. Univ.) described work in his group on new Mg-alloys for 
structural applications. High-temperature casting and wrought $\mathrm{Mg}$ alloys are required for various applications in the automobile industry, and $\mathrm{Mg}-\mathrm{Al}$ alloys have been used for this purpose. However, this resulted in the formation of the intermetallic $\mathrm{Mg}_{17} \mathrm{Al}_{12}$ beta phase which has a cubic structure compared to the hcp structure of the matrix; moreover, it has a low melting point of $450^{\circ} \mathrm{C}$. This phase thus weakens the grain boundaries at elevated temperatures. The effect of adding $\mathrm{Sn}, \mathrm{Sr}, \mathrm{Ca}, \mathrm{Si}$, and $\mathrm{Mn}$ to suppress the formation of this beta phase was investigated. In particular, the addition of tin (Sn) to $\mathrm{Mg}-\mathrm{Al}$ alloys formed $\mathrm{Mg}_{2} \mathrm{Sn}$ and $\mathrm{Mg}_{17} \mathrm{Al}_{12}$ phases, and the stability of these resulted in good high-temperature mechanical properties of die-cast $\mathrm{Mg}$-Sn$\mathrm{Al}$ alloys. The addition of $\mathrm{Sr}, \mathrm{Ca}, \mathrm{Si}$, and Mn yielded formation of thermally stable precipitates at grain boundaries, and the combined addition of these elements to the $\mathrm{Mg}-\mathrm{Sn}-\mathrm{Al}$ alloy significantly improved the high-temperature mechanical properties.

\section{Biomaterials}

Coronary stents are often used to prop open the coronary artery to allow blood to flow when blockages are found. The first generation of such devices included bare metal stents. However, such permanent implants can lead to chronic inflammatory reactions and increased the risk of late thrombosis and rebound narrowing of the artery. Second-generation coated drug-eluding stents can show improved behavior, but completely absorbable biocompatible polymers are expected to minimize these risks still further. By bioabsorbing after 6-9 months, the device cannot cause late-stage risk, because the device is no longer there. In Symposium I on Biomaterials for Medical Applications, K. Ulrich (Rutgers Univ.) presented developments on such stents. She described a salicylate-based bioabsorbable polymer eluting sirolimus developed by Bioabsorbable Therapeutics, Inc. (BTI). In clinical tests in pig coronary arteries, the bioresorbable stents were compared to bare metal and coated stents. The polymer stent has a strong radial strength to start, but this strength is reduced over time. After one week, the polymer starts to break down, and after four weeks, tissue regeneration takes hold. After nine months the stent has eroded and the tissue has regenerated. The first clinical stents have now been put in humans, and results were pending as of the time of the conference.

X.-Z. Zhang (Wuhan Univ.) also ven- tured into the intersection between polymers and biomaterials as he examined micelle drug delivery systems to attack tumor cells. He described a novel amphiphilic tris(dibenzoylmethanato) europium(III) $\left(\mathrm{Eu}(\mathrm{DBM})_{3}\right)$ coordinated P(MMA-co-EIPPMMA)-co-P(NIPAAm-coNDAPM) copolymer system with fluorescent properties for tracking and thermal sensitivity for cellular internalization and drug release (MMA, methyl methacrylate; EIPPMMA, 4-(1-ethyl-1H-imidazo[4,5$f][1,10]$ phenanthrolin-2-yl)phenyl methacrylate; NIPAAm, $N$-isopropylacrylamide; NDAPM, (N-(3-dimethylamino) propyl)methacrylamide). The micelles of the copolymer are $\sim 250 \mathrm{~nm}$ and are well dispersed as individual regularly sphericalshaped nanoparticles. A structural change to the micelles is induced at $36.8^{\circ} \mathrm{C}$, and heating through this transition led to significantly faster drug release. The emissions spectrum of the copolymer showed a strong sharp peak at $620 \mathrm{~nm}$. The cellular internalization of the micelles was further investigated by a laser scanning confocal microscope and the micelles can internalize into the A549 tumor cells. The drug-loaded micelles inhibited the growth of A549 cells. In vitro studies of drug-loaded micelles showed an antitumor effect in A549 tumor cells, with $80 \%$ of the cells killed. To have a targeted effect, target ligands are added to the copolymer, for instance with biotin. Uptake is enhanced with the use of target ligands. As of the time of the conference, in vivo studies were still in progress on male adult Wistar rats.

Conducting polymers provide interesting surfaces for bone implants because their surface properties can be modified to release drugs by redox reactions. S. Sirivisoot (Brown Univ.) described the electropolymerization of pyrrole with drugs on Ti substrates, providing a new cytocompatible surface for bone implants. Penicillin/streptomycin and dexamethasone were individually incorporated within polypyrrole (PPy) thin films. Drug release was triggered by electrical potential to the biofilm on the Ti substrate, which represents a hip joint implant. Preliminary in vitro results with human osteoblasts demonstrated greater adhesion after 4 hours on PPy-drug-embedded films, while the number of fibroblasts that adhered decreased compared to conventional Ti.

Rotator cuff tears in the shoulder can cause significant pain and disability. In the United States, 300,000 surgeries are performed each year, yet $60 \%$ of repairs fail. Typical repairs involve autographs (tissues taken from elsewhere in one's body) or freeze-dried allografts (tissues 
from cadavers). A serious concern with rotator cuff tears is the limited healing potential of the tendon tissue, and surgeons are exploring alternative management options such as partial cuff repair, surgical debridement without repair, and conservative treatment with physical therapy alone. However, clinical results are still sub-optimal, with pre-injury function not achieved. In addition, several factors limit the extensive use of biologi- cal grafts including donor site morbidity, limited availability of autograft tissue, the risk of disease transmission from allografts, and loss of mechanical strength of the synthetic patch grafts as they cause adverse reactions over time, according to C.T. Laurencin (Professor and Chair of Orthopaedic Surgery at the University of Virginia). Laurencin presented an alternative approach using tissue engineering to provide initial strength to a torn rotator

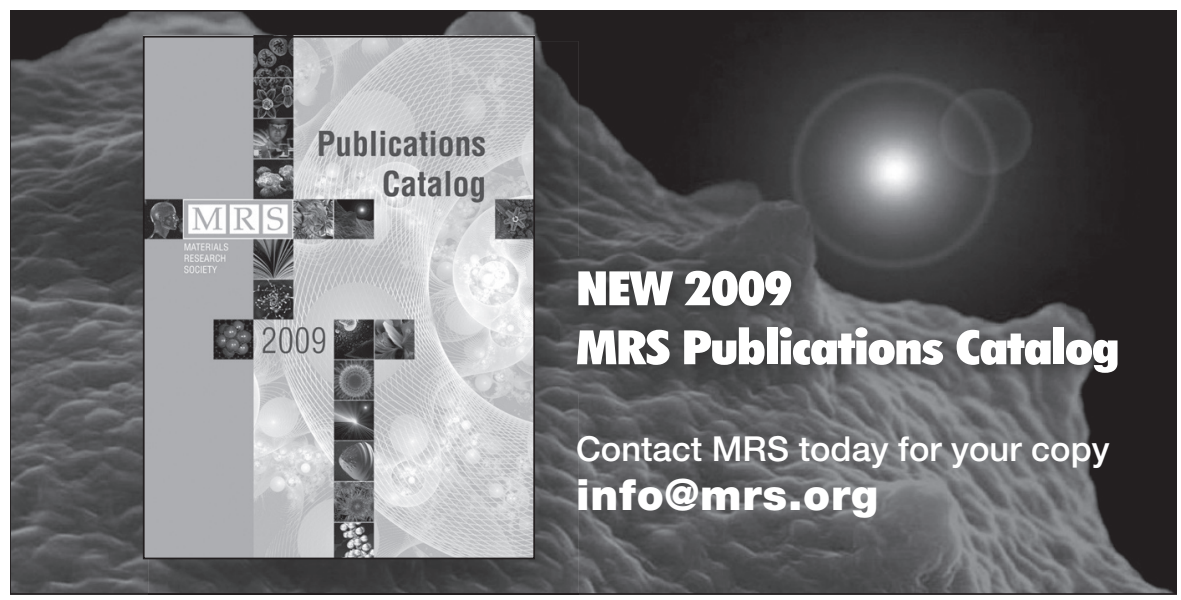

cuff and enhance the rate of regenerative repair. The extracellular matrix can be mimicked using polymeric nanofibers. These porous materials with fibers with high aspect ratios are conducive to cell attachment and proliferation. The matrices are created through an electrospinning process of poly(lactic acid-co-glycolic acid). The process creates a randomly oriented nanofiber mat that is bioresorbable. In vitro studies on samples seeded with tendon cells from a rabbit showed rapid adhesion (clearly visible on Day 3), cell viability, cell proliferation (started by Day 7, and well established after four weeks), and elastic modulus strength superior to other alternatives. An optimal area of 500-900 nm was found to maximize cell proliferation. A rat model was found to be best for in vivo studies, with significant increases in mechanical strength obtained at the eight-week interval. Laurencin dedicated this presentation to Judah Folkman, M.D., 1933-2008, "mentor, family man, and humanist."

For additional meeting highlights provided by the MRS Meeting Scenes, see the 2008 International Materials Research Conference Web site at www.mrs. org/IMRC2008.

M|RTS

\section{CAMBRIDGE}

\section{The Material World \\ Rodney Cotterill \\ \$50.00: Hb: 978-0-521-45147-5: 576 pp. Discount Price: $\mathbf{\$ 4 0 . 0 0}$}

\section{Structure of Materials}

An Introduction to Crystallography, Diffraction and Symmetry

Marc De Graef and

Michael E. McHenry

\$95.00: Hb: 978-0-521-65151-6: 876 pp.

Discount Price: $\$ 76.00$

Now in Paperback!

Thin Film Materials

Stress, Defect Formation and

Surface Evolution

L. B. Freund and S. Suresh

\$70.00: Pb: 978-0-521-52977-8: 768 pp.

Discount Price: $\$ 56.00$

\section{New and Exciting Titles!}

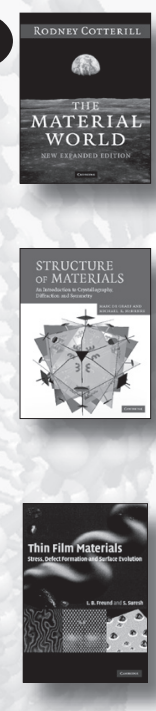

\section{Carbon Nanotube}

Science

Synthesis, Properties and

Applications

Peter J. F. Harris

\$90.00: Hb: 978-0-521-82895-6: 328 pp. Discount Price: $\$ 72.00$

\section{Materials for}

Engineers

William F. Hosford

\$85.00: Hb: 978-0-521-89997-0: $296 \mathrm{pp}$ Discount Price: $\$ 68.00$

\section{Viscoelastic \\ Materials}

Roderic Lakes

\$125.00: Hb: 978-0-521-88568-3: $480 \mathrm{pp}$ Discount Price: $\$ 100.00$

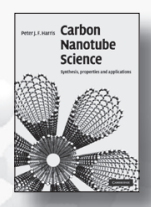

Mechanical Behavior of Materials

Marc André Meyers and

Krishan Kumar Chawla

\$90.00: Hb: 978-0-521-86675-0: 880 pp. Discount Price: $\$ 72.00$
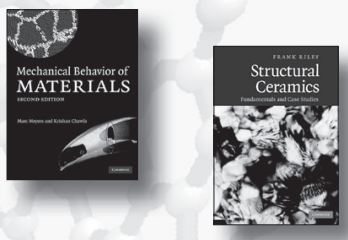

Structural Ceramics

Fundamentals and Case Studies

Frank Riley

\$90.00: $\mathrm{Hb}:$ 978-0-521-84586-1: $392 \mathrm{pp}$.

Discount Price: $\$ 72.00$

Enter promotion code MRS09 at checkout to save $20 \%$ on these titles for a limited time only!

www.cambridge.org/us/engineering

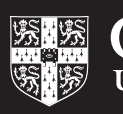

CAMBRIDGE UNIVERSITY PRESS
I $584 \cdot 2009$

425 YEARS OF CAMBRIDGE PRINTING AND PUBLISHING 